\title{
Ovarian carcinoma diagnosis: the clinical impact of 15 years of change
}

\author{
Stefan Kommoss ${ }^{\star}, 1$, C Blake Gilks ${ }^{2}$, Andreas du Bois ${ }^{3,5}$ and Friedrich Kommoss ${ }^{2,4,5}$ \\ ${ }^{1}$ Department of Women's Health, Tübingen University Hospital, Calwerstrasse 7, 72076 Tübingen, Germany; ${ }^{2}$ Department of \\ Pathology and Laboratory Medicine, University of British Columbia, 910 West 10th Avenue, Vancouver, BC, Canada V5Z 4E3; \\ ${ }^{3}$ Department of Gynecology and Gynecologic Oncology, Kliniken Essen Mitte (KEM), Henricistraße 92, 45136 Essen, Germany and \\ ${ }^{4}$ Institute of Pathology, Referral Centre for Gynecopathology, A2/2, 68159 Mannheim, Germany
}

Background: Until recently ovarian carcinoma was considered to be a single disease, and treatment decisions were based solely on grade and pre- and postoperative tumour burden. New insights into molecular features, treatment response, and patient demographics led the scientific community to conclude that ovarian carcinoma histotypes are different disease entities.

Methods: In 2002, the pathology specimens from patients in a clinical trial were reviewed by an experienced gynaecopathologist (pathologist A) for translational research purposes. All cases were typed according to what were then current criteria. The identical cohort was now reassessed by the same expert pathologist and independently reviewed by another gynaecopathologist (pathologist B) applying WHO 2014 diagnostic criteria. Survival analyses were done based on the original as well as the new diagnoses, and historical biomarker study results were recalculated.

Results: Upon re-review, pathologist A rendered the same histotype diagnosis in only $54 \%$ of cases. In contrast, pathologists A and B independently rendered the same diagnosis in 98\% of cases. Histotype was of prognostic significance when 2014 diagnoses were used, but was not prognostic using the original (2002) histotype diagnoses.

Conclusions: Our study demonstrates a marked shift in ovarian carcinoma histotype diagnosis over the past 15 years. The new criteria are associated with a very high degree of interobserver reproducibility, allowing for treatment decisions based on histotype. Finally, biomarkers of putative prognostic significance were revealed to be primarily histotype-specific markers, confirming the critical importance of obtaining up-to-date diagnoses rather than accepting archival histotype data in clinical research.

In the past ovarian carcinoma was regarded as to be a single entity with a spectrum of disease in which well-differentiated carcinoma progressed to poorly differentiated tumours (Kurman and Shih Ie, 2011). Moreover, histopathological ovarian carcinoma typing was afflicted with only modest reproducibility (Kobel et al, 2014). Treatment decisions were based solely on tumour stage (pre-operative tumour burden), post-operative tumour residuals, and grade. Novel therapeutic approaches to ovarian carcinoma were hindered by a poor understanding of the molecular heterogeneity of the disease, thus patients are today still treated according to a 'one size fits all' approach: tumour debulking surgery aiming at the complete resection of all tumour visible and cytotoxic chemotherapy based on platinum and taxanes. However, over the last two decades studies on ovarian carcinoma morphology, immunohistochemistry, and molecular genetics have led to the proposal that histotypes of ovarian carcinoma are best considered to be separate disease entities differing with respect to precursor lesions, molecular events during oncogenesis, pattern of spread, response to chemotherapy, and outcome (Kobel et al, 2008; McCluggage, 2011; Prat, 2012a). New insights into ovarian carcinoma pathology are driving change in ovarian carcinoma diagnoses and have recently served to modify the WHO

\footnotetext{
*Correspondence: Dr Stefan Kommoss; E-mail: stefan.kommoss@med.uni-tuebingen.de

${ }^{5}$ These authors contributed equally to this work.
}

Received 20 May 2016; revised 26 July 2016; accepted 1 August 2016; published online 15 September 2016

(c) 2016 Cancer Research UK. All rights reserved 0007-0920/16 
Classification of Ovarian Tumors. According to the current 2014 classification epithelial ovarian cancer comprises five major histological types namely high-grade serous (HGSC), low-grade serous (LGSC), endometrioid (EC), clear cell (CCC), and mucinous ovarian carcinoma (MC) (Kurman et al, 2014). In contrast, the former 2003 WHO classification divided ovarian carcinoma into eight different histological types namely serous, EC, CCC, MC, transitional cell, squamous cell, mixed type, and undifferentiated ovarian carcinoma. Furthermore, HGSC and LGSC were not recognised as being separate histological types, but rather considered to represent different grades of one tumour entity (Tavassoli and Devilee, 2003).

Accurate histological typing taking into account recent diagnostic developments already has a key role in ovarian carcinoma research and will furthermore become indispensable clinically as there is a move towards histotype-specific treatment (McAlpine et al, 2009; Anglesio et al, 2012).

It was the aim of this study to assess how the evolution of histological ovarian carcinoma diagnostic criteria have influenced histotype diagnosis made by gynaecopathological experts and what were the likely clinical impact of such changes. In order to do so, a clinical trial cohort, which had undergone expert gynaecopathology case review in 2002, was now rereviewed by the same pathologist (FK). Results were then compared with the results of independent review by another expert gynaecopathologist (BG). Furthermore, we hypothesised that revisiting historical survival analyses and biomarker studies using current diagnoses might lead to previously unexpected original new findings. Data from a previously published study showing independent prognostic significance of p16(INK4a) and $\mathrm{pRb}$ in advanced-stage ovarian carcinoma were recalculated (Kommoss et al, 2007).

\section{MATERIALS AND METHODS}

Tumour samples collected for translational research purposes from the AGO OVAR3 trial (prospective randomised, multi-centre, phase III trial comparing cisplatin + paclitaxel $v s$ carboplatin + paclitaxel in FIGO IIB-IV ovarian carcinoma patients) formed the basis of the current study (du Bois et al, 2003). In 2002 central pathology review of a series of 334 study patients was performed by pathologist A (FK), established referral centre gynaecopathologist at that time. After exclusion of tumour samples insufficient for diagnosis of invasive ovarian carcinoma a series of 302 cases were available for further analysis. Tumours were typed according to the then current $\mathrm{WHO}$ criteria and were classified as either serous, MC, EC, CCC, transitional cell or undifferentiated ovarian carcinoma (Scully, 1999; Tavassoli and Devilee, 2003; Kommoss et al, 2005). Tumour grade was assessed according to the FIGO grading system (International Federation of Obstetrics and Gynecology, 1971).

Twelve years later all original slide material from the same cohort was re-reviewed by pathologist A, applying current diagnostic criteria. An independent review was performed by pathologist B (BG), another internationally recognised expert gynaecopathologist. Both pathologists were blinded to the original 2002, as well as to each other's current diagnoses. According to the 2014 WHO criteria carcinomas were now typed as either HGSC, LGSC, EC, CCC, and MC (Kurman et al, 2014). Any discrepancies arising between current diagnoses of pathologist $\mathrm{A}$ and the evaluation of pathologist B were discussed on a case-by-case basis.

Kaplan Meier survival analysis based on original diagnoses of pathologist A was compared with that using current final consensus diagnoses of pathologists A and B. A historical biomarker study data set was retrieved and statistics were recalculated using the same consensus histotyping data (Kommoss et al, 2007).

\section{RESULTS}

Upon retrieval of original study material from the AGO OVAR3 trial series, historical 2002 pathology review data and all pertaining original histological slides of 286 out of 302 cases were available. In comparison with the original review diagnoses, the distribution of histological types differed considerably both after re-review by pathologist $\mathrm{A}$, as well as after independent review by pathologist $\mathrm{B}$ (Figure 1). Taking all histotypes together, pathologist A confirmed only 155 out of 286 (54\%) of his specific histotype diagnoses. In the original review, 131 out of $286(46 \%)$ of cases had been assigned to the serous type. At that time serous carcinomas were regarded as a single tumour entity of varying tumour grade (G1: 26 out of 131 (20\%); G2: 71 out of 131 (54\%); and G3: 34 out of 131 (26\%). The distribution of non-serous carcinoma types was as follows: MC, 23 out of 286 (8\%); EC, 52 out of 286 (18\%); CCC, 35 out of 286 (12\%); transitional cell, 14 out of 286 (5\%); and undifferentiated, 31 out of 286 (11\%). In keeping with current WHO criteria, tumours with serous differentiation were classified as either being of HGSC or LGSC type upon re-review by pathologist A, HGSC (229 out of $286 ; 80 \%$ ) now being the most frequent histological type. The distribution of histological types among the remaining cases was as follows: LGSC, 21 out of $286(7 \%)$; MC, 9 out of 286 (3\%); EC, 14 out of 286 (5\%); and CCC, 13 out of $286(5 \%)$.

Comparing pathologist A's original and current histotype diagnoses, all cases with an original diagnosis of undifferentiated $(n=31)$ and transitional cell carcinoma $(n=14)$ were reclassified as HGSC. In the remaining cases, a diagnostic shift to different histotypes was observed in varying percentages, the most frequently found being serous (any grade) $\rightarrow$ HGSC (112 out of $131,85 \%), \mathrm{EC} \rightarrow$ HGSC (40 out of $52,77 \%$ ), and CCC $\rightarrow$ HGSC ( 22 out of 35,62\%). Examples of cases of HGSC, based on 2014 review, that were previously diagnosed as CCC and endometrioid ovarian carcinoma are given in Figure 2.

Subgroup analyses of those tumours diagnosed as serous carcinomas (any grade) in 2002 showed that all G3 (34 out of $34,100 \%$ ) and the vast majority of G2 tumours (70 out of $71,99 \%$ ) were diagnosed as HGSC. In contrast the G1 tumours were diagnosed on re-review as HGSC (8 out of 26, 23\%) and LGSC (18 out of $26,62 \%$ ), respectively.

The relative frequency of histological types according to independent review by pathologist $B$ was almost identical to that after pathologist A's 2014 re-review: HGSC, 233 out of 286 (81\%); LGSC, 21 out of 286 (7\%); MC, 9 out of 286 (3\%); EC, 10 out of 286 (4\%); and CCC, 13 out of 286 (5\%). For comparison of the historical 2002 review by pathologist A, his 2014 re-review and the 2014 independent review by pathologist B see Table 1 .

Comparing pathologist A's and pathologist B's 2014 diagnoses there was a concordance of histotype diagnosis in 280 out of 286 (98\%) cases. Of the six discrepant cases, pathologist A diagnosed four as being of EC type (pathologist B: all HGSC), one as being HGSC (pathologist B: LGSC), and one as being LGSC (pathologist B: HGSC), as shown in Figure 1.

After online case discussion, based on scanned H\&E sections and taking into consideration an additional WT1 immunostain in one case, a diagnostic consensus was reached in all six discrepant cases (HGSC, $n=5$; endometrioid, $n=1$ ).

Survival analyses based on pathologist A's 2002 findings showed a significantly better survival for patients with a diagnosis of transitional cell carcinoma, with the other histotypes being of no prognostic significance. Applying 2014 diagnostic consensus data, 


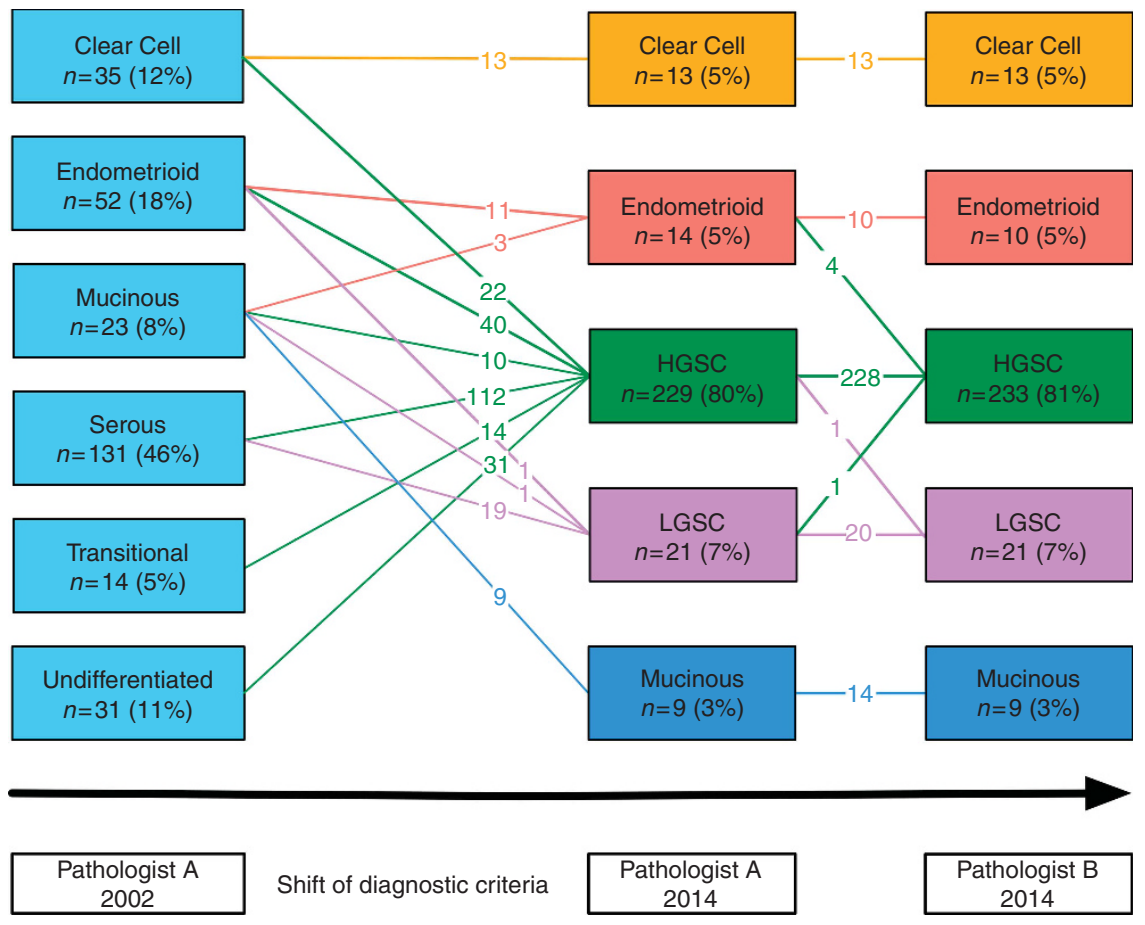

Figure 1. Histological types in a series of 286 ovarian carcinomas after pathological review in 2002 (pathologist A 2002, left column) as compared with re-review applying current diagnostic criteria by the same reviewer (pathologist A 2014, middle column) and by another expert (pathologist B, right column).

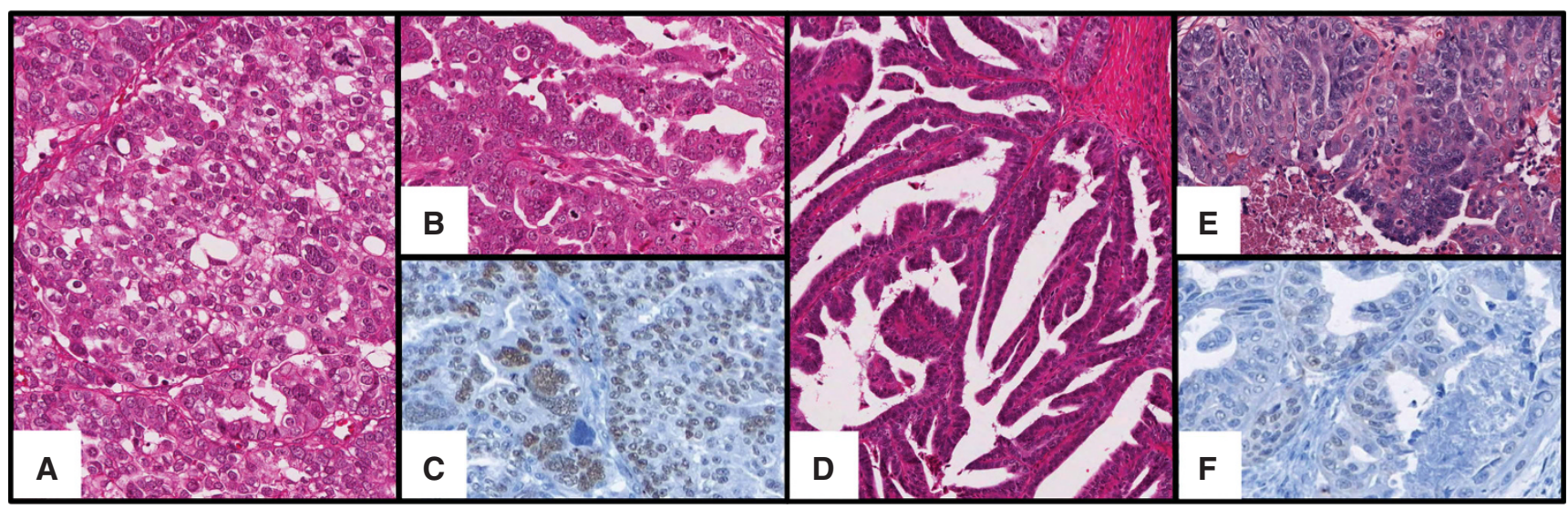

Figure 2. Examples of cases of HGSC, based on 2014 review, that were previously diagnosed as CCC and EC. (A-C) The 2014 review HGSC, diagnosed as CCC in 2002. (A) Cells with clear cytoplasm, suggestive of CCC. (B) Typical architectural and cytological features of HGSC from elsewhere in this tumour. (C) Moderately intense diffuse WT1 immunopositivity. (D-F) The 2014 review HGSC, diagnosed as EC in 2002. (D) Villoglandular architecture suggestive of endometrioid ovarian carcinoma. Note absence of squamous differentiation. (E) Typical architectural and cytological features of HGSC from elsewhere in this tumour. (F) Focal weak but convincing WT1 immunopositivity.

MC and CCC showed a significantly worse outcome as compared with HGSC, LGSC, and EC (Figure 3).

Taking this new prognostic information into consideration the prognostic significance of $\mathrm{p} 16$ and $\mathrm{pRb}$ expression data were also reevaluated. Type-specific analyses of historical p16 and pRb expression data showed no significant correlation of 2002 original diagnoses and biomarker expression (Figure $4 \mathrm{~A}$ and $\mathrm{B}$ ). However, p16 negativity and high levels of pRb expression, both originally described as being indicative of an unfavourable outcome (any histotype), were found to be significantly more often present in CCC and MC (Figure 4C and D), with overall worse prognosis in $\mathrm{pRb}$ high cases. While previously published data showed a worse prognosis for p16 negative cases (all histotypes), p16 negativity now indicated a prognostic disadvantage only in the subgroup of CCC and MC, whereas in all other histotypes it conveyed no significant prognostic information (Figure 5).

\section{DISCUSSION}

The subclassification of ovarian carcinomas has been routinely based on histopathological features, specifically the resemblance of tumour cells to different cellular lineages characteristic of the mullerian tract, for example, fallopian tube, endometrium, or endocervix, as this classification system was formally proposed by the WHO in the 1970s (Poulsen et al, 1975). Shortly after the 
Table 1. Distribution of ovarian carcinoma histotypes according to historical 2002 review, current 2014 re-review by pathologist A, and 2014 independent review by pathologist B

\begin{tabular}{|c|c|c|c|c|c|c|c|c|}
\hline \multicolumn{3}{|c|}{ Pathologist A 2002/WHO, 1999} & \multicolumn{3}{|c|}{ Pathologist A 2014/WHO, 2014} & \multicolumn{3}{|c|}{ Pathologist B 2014/WHO, 2014} \\
\hline Serous G1/G2/G3 & $n=131$ & $46 \%$ & HGSC & $n=229$ & $80 \%$ & HGSC & $n=233$ & $81 \%$ \\
\hline EC & $n=52$ & $18 \%$ & LGSC & $n=21$ & $7 \%$ & LGSC & $n=21$ & $7 \%$ \\
\hline $\mathrm{CCC}$ & $n=35$ & $12 \%$ & EC & $n=14$ & $5 \%$ & EC & $n=10$ & $4 \%$ \\
\hline Undifferentiated & $n=31$ & $11 \%$ & $\mathrm{CCC}$ & $n=13$ & $5 \%$ & $\mathrm{CCC}$ & $n=13$ & $5 \%$ \\
\hline MC & $n=23$ & $8 \%$ & MC & $n=9$ & $3 \%$ & $\mathrm{MC}$ & $n=9$ & $3 \%$ \\
\hline TCC & $n=14$ & $5 \%$ & & & & & & \\
\hline
\end{tabular}
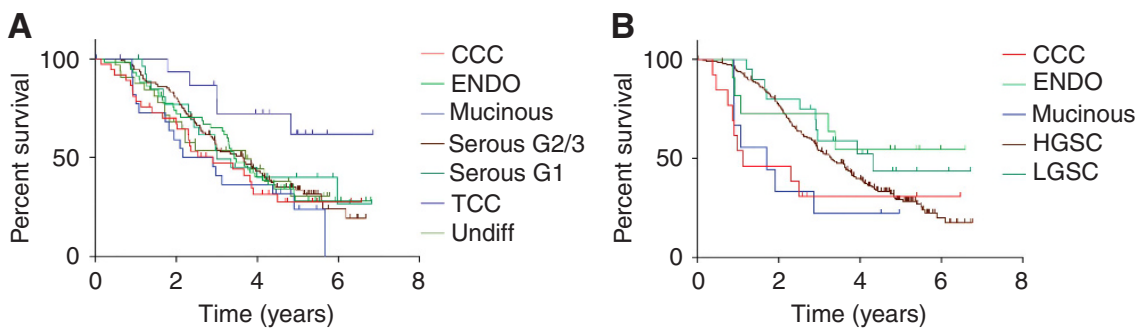

Figure 3. Survival by ovarian carcinoma histotype. (A) Survival using 2002 review diagnoses. Significantly better survival for TCC, the other histotypes of no prognostic significance. (B) Survival using 2014 consensus diagnoses. Significantly worse prognosis for MC and CCC as compared with HGSC, LGSC and ENDO.

A

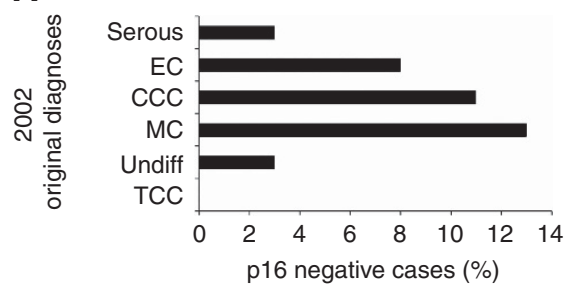

C

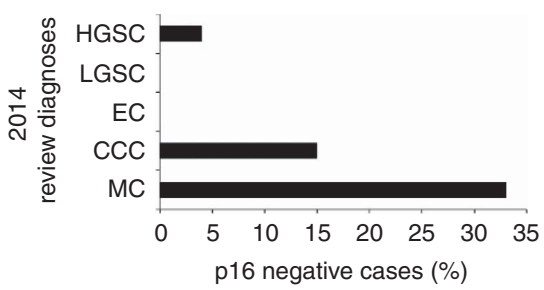

B

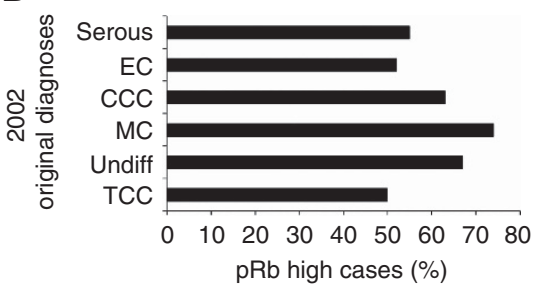

D

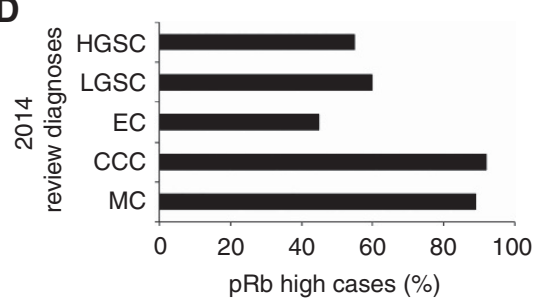

Figure 4. Biomarker expression by histotype. (A) p16 negative cases, 2002 diagnostic criteria. No significant correlation with histotype ( $P=0.09)$. (B) pRb high cases, 2002 diagnostic criteria. No significant correlation with histotype $(P=0.4)$. (C) p16 negative cases, 2014 diagnostic criteria. CCC and MC significantly more often p16 negative $(P=0.007)$. (D) pRb high cases, 2014 diagnostic criteria. CCC and MC significantly more often pRb high $(P=0.009)$.

introduction of this classification scheme it was demonstrated that there was only moderate interobserver reproducibility in assignment of histotype, and there was also an appreciation that many cases showed considerable intratumoral heterogeneity in morphological appearance, resulting in many being diagnosed as mixed carcinoma, that is, consisting of an admixture of different histotypes (Mackenzie et al, 2015). The lack of reproducibility meant that histotype could not be used as a basis for patient management, while the frequent diagnosis of mixed carcinoma suggested that the histotypes were very closely related entities, often intermingling in an individual case, further evidence that went against considering histotype-specific patient management. The practice of considering ovarian carcinoma as a single disease with subtle morphological variants of little or no clinical significance was widespread until recently (Fletcher, 2013).

It was appreciated a decade ago that the mucinous and clear cell histotypes were associated with a less-favourable response to chemotherapy, and a concensus panel suggested that histotypespecific treatments should be developed for these histotypes (Fountain et al, 2006). At the same time, there was (1) development of histotype specific biomarkers, such as WT1, a marker of serous differentiation (Acs et al, 2004); (2) recognition based on morphology and clinicopathological correlation that HGSC and LGSC are distinct diseases (Singer et al, 2002; Malpica et al, 2004); and (3) increasing awareness that mixed carcinomas are uncommon, with many cases so diagnosed in the past simply 
A

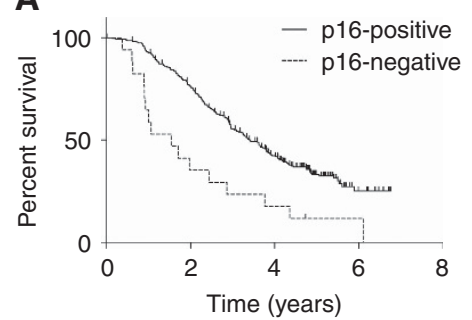

B

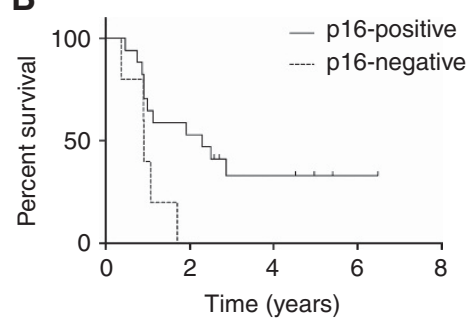

C

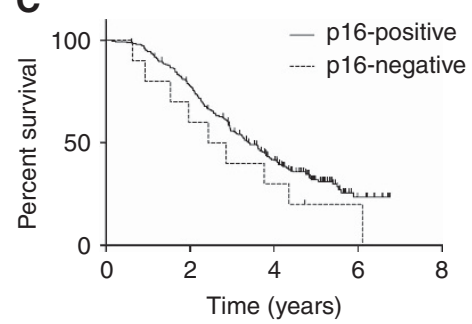

Figure 5. Kaplan Meier survival estimates for p16 expression. (A) Published data applying 2002 diagnostic criteria, all histological types ( $n=286$ ) (Kommoss et al, 2007). Significantly worse prognosis for p16 negative patients $(P<0.001)$. (B) The 2014 review CCC and MC types only ( $n=22)$. Significantly worse prognosis for p16-negative patients $(P=0.02)$. (C) The 2014 review HGSC, LGSC, and EC types only ( $n=264)$. p16 of no prognostic significance $(P=0.17)$.

being HGSCs with intratumoral morphological heterogeneity (Mackenzie et al, 2015); these developments led to demonstrable improvements in intraobserver reproducibility of ovarian carcinoma diagnosis. This is the first study, however, where both the shift of histotype diagnosis and the improvement in diagnostic reproducibility have been quantified, comparing diagnoses made previously, according to the criteria in use 15 years ago to current criteria. A well-defined set of cases from a clinical trial was used, with the same gynaecopathologist reviewing the cases 15 years later, allowing assessment of intraobserver diagnostic shift. As well, the histotype diagnoses rendered independently by two gynaecopathologists applying current diagnostic criteria, but working completely independently (different countries/continents, no common training bias/had never practiced in the same centre, or viewed cases together before this study) were compared. We have shown a very marked shift in diagnoses with only $54 \%$ intraobserver agreement in histotype diagnosis from 2002 to 2014 . This reflects the profound effect over time new insights into the biology and morphology have had on the histopathological evaluation of ovarian carcinoma, as reflected in the current (WHO, 2014) classification system. In contrast, there is near perfect (98\%) interobserver agreement in histotype diagnosis between two gynaecopathologists using current diagnostic criteria. This latter level of agreement exceeds the diagnostic accuracy demanded for predictive biomarkers such as HER2 testing, where 95\% accuracy is required, according to the ASCO-CAP guidelines (Wolff et al, 2013), and places histotype diagnostic accuracy within the realm, where reproducibility is sufficient to allow for histotype specific management, such as placing patients into histotype-specific clinical trials.

The five main histotypes of ovarian carcinoma differ with respect to precursor lesions, molecular events during oncogenesis, genetic risk factors/association with hereditary cancer syndromes, patterns of spread, response to chemotherapy, and patient outcomes (Prat, 2012b). These differences were obscured in the past, when histotype was not accurately diagnosed. For example, within the clinical trial cases we report on, histotype only becomes of prognostic significance with the 2014 diagnoses, where MC and CCC are associated with a worse prognosis. These results show clearly the inadequacy of using historical diagnoses for research purposes, even when rendered by an experienced gynaecopathologist. This can also be seen in the results of the CIMBA study, where ovarian carcinoma histotype of more than 3000 ovarian carcinomas arising in patients with BRCA1 or BRCA2 mutations was reported (Mavaddat et al, 2012). The diagnoses were not based on re-review with use of current diagnostic criteria, and $<70 \%$ of tumours were reported as being serous. In contrast, in case series with pathology re-review and use of current diagnostic criteria, almost all BRCA1 or BRCA2 associated ovarian carcinomas are high-grade serous type (Schrader et al, 2012). The impact of accurate histotype diagnosis on biomarker research is also demonstrated in our results; our previously reported association between pRB and p16 and prognosis (Kommoss et al, 2007) is seen to be largely attributable to correlation of expression of these markers with the unfavourable clear cell and mucinous histotypes, a finding obscured when the earlier, less-accurate histotype diagnoses were used. For biomarker studies to be interpretable it is critical that there be analysis with histotypes considered separately, and that histotype diagnoses be made based on current diagnostic criteria; historical histotype diagnoses are worse than useless, and can lead to incorrect conclusions. One can see prognostic significance when there is none, as for $\mathrm{pRB}$ or $\mathrm{p} 16$, or using histotype diagnosis important prognostic relationships may be obscured, as we demonstrated previously, that is, T-cell infiltrates are of prognostic significance in HGSC, but are not significant when all histotypes are considered together (Clarke et al, 2009). Cancer diagnoses have undergone a revolution over the past decade, with the ability to subdivide 'common' cancers into subtypes with distinct molecular profiles. This is perhaps best established for breast carcinoma, where it would be inconceivable to plan treatment without assessment of hormone receptor and HER2 status, but has also emerged for many other solid tumour types that, such as ovarian carcinoma, were formerly considered monolithic. For example, renal cell carcinoma can also be subdivided into histotypes based primarily on H\&E assessment, with judicious use of immunohistochemistry and/or molecular testing in selected cases (Srigley et al, 2013). Ovarian carcinoma differs from breast but is similar to renal carcinomas in that a primarily morphological classification, with molecular testing as adjunct in selected cases, allows diagnosis of the molecular subtypes. There is no such thing as 'ovarian carcinoma' and we must look to generate new data defining the natural history, including response to treatment, of the ovarian carcinoma histotypes, as the older literature, where histotype diagnoses were based on historic criteria, or there was no attempt to separate cases based on histotype, is meaningless.

Our data demonstrate how much ovarian carcinoma histotype diagnosis has evolved over recent years, and begs the question of whether this trend will continue. We believe that the current histotypes will be stable into the future, and will not continue to change markedly. Our belief that the histotypes, as currently defined, are stable diagnostic categories, is based on the extensive molecular classification that has been done that supports them being distinct entities, as well as the corroborating clinical studies demonstrating, as seen in our results, differences in response to treatment and outcomes for the different histotypes. This has important implications; for example, it would be appropriate to revisit old data sets, in order to better characterise the histotypes with respect to response to treatment. In the future we can anticipate better understanding of the histotypes; while new prognostic and predictive markers will emerge, they will almost certainly prove to be histotype specific, and treatment will continue to evolve in the direction of histotype-specific 
therapies. The very reproducible diagnosis of histotype that we have shown supports histotype as a basis for ovarian carcinoma subclassification. This situation for ovarian carcinoma is different from that of EC, where histotype cannot be reproducibly diagnosed, or breast carcinoma, where 15 years after description of basal-like carcinomas they are not consistently diagnosed in routine practice; for both endometrial and breast carcinoma further refinement of histotype diagnosis can be anticipated. In contrast, for ovarian carcinoma we now have reproducibly diagnosable and molecularly distinct histotype and it is completely unacceptable to use historical histotype diagnoses for research purposes. It is time to start over, and our understanding of ovarian carcinomas must be based on accurate histotype diagnosis using current criteria.

\section{CONFLICT OF INTEREST}

The authors declare no conflict of interest.

\section{REFERENCES}

Acs G, Pasha T, Zhang PJ (2004) WT1 is differentially expressed in serous, endometrioid, clear cell, and mucinous carcinomas of the peritoneum, fallopian tube, ovary, and endometrium. Int J Gynecol Pathol 23(2): $110-118$.

Anglesio M, Kommoss S, Tolcher M, Clarke B, Galletta L, Porter H, Damaraju S, Fereday S, Winterhoff B, Kalloger S, Senz J, Yang W, Steed H, Allo G, Ferguson S, Shaw P, Teoman A, Garcia J, Schoolmeester J, BakkumGamez J, Tinker A, Bowtell D, Huntsman D, Gilks C, McAlpine J (2012) Molecular characterization of mucinous ovarian tumors supports a stratified treatment approach with HER2 targeting in 18\% of carcinomas. J Pathol 229(1): 111-120.

Clarke B, Tinker AV, Lee CH, Subramanian S, van de Rijn M, Turbin D, Kalloger S, Han G, Ceballos K, Cadungog MG, Huntsman DG, Coukos G, Gilks CB (2009) Intraepithelial T cells and prognosis in ovarian carcinoma: novel associations with stage, tumor type, and BRCA1 loss. Mod Pathol 22(3): 393-402.

du Bois A, Luck HJ, Meier W, Adams HP, Mobus V, Costa S, Bauknecht T, Richter B, Warm M, Schroder W, Olbricht S, Nitz U, Jackisch C, Emons G, Wagner U, Kuhn W, Pfisterer J. Arbeitsgemeinschaft Gynakologische Onkologie Ovarian Cancer Study G (2003) A randomized clinical trial of cisplatin/paclitaxel versus carboplatin/paclitaxel as first-line treatment of ovarian cancer. J Natl Cancer Inst 95(17): 1320-1329.

Fletcher C (2013) Diagnostic Histopathology of Tumors. 4th edn (Churchill Livingston: Philadelphia, PA, USA.

Fountain J, Trimble E, Birrer MJ (2006) Recommendations of the 2005 Ovarian Cancer State of the Science Meeting. Gynecol Oncol 103 (2 Suppl 1): S26.

International Federation of Obstetrics and Gynecology (1971) Classification and staging of malignant tumors in the female pelvis. Acta Obstet Gynecol Scand 50: 1-7.

Kobel M, Bak J, Bertelsen BI, Carpen O, Grove A, Hansen ES, Levin Jakobsen AM, Lidang M, Masback A, Tolf A, Gilks CB, Carlson JW (2014) Ovarian carcinoma histotype determination is highly reproducible, and is improved through the use of immunohistochemistry. Histopathology 64(7): 1004-1013.

Kobel M, Kalloger SE, Boyd N, McKinney S, Mehl E, Palmer C, Leung S, Bowen NJ, Ionescu DN, Rajput A, Prentice LM, Miller D, Santos J, Swenerton K, Gilks CB, Huntsman D (2008) Ovarian carcinoma subtypes are different diseases: implications for biomarker studies. PLoS Med 5(12): e232.

Kommoss F, Kommoss S, Schmidt D, Trunk MJ, Pfisterer J, du Bois A (2005) Survival benefit for patients with advanced-stage transitional cell carcinomas vs. other subtypes of ovarian carcinoma after chemotherapy with platinum and paclitaxel. Gynecol Oncol 97(1): 195-199.

Kommoss S, du Bois A, Ridder R, Trunk MJ, Schmidt D, Pfisterer J, Kommoss F (2007) Independent prognostic significance of cell cycle regulator proteins p16(INK4a) and pRb in advanced-stage ovarian carcinoma including optimally debulked patients: a translational research subprotocol of a randomised study of the Arbeitsgemeinschaft Gynaekologische Onkologie Ovarian Cancer Study Group. Br J Cancer 96(2): 306-313.

Kurman RJ, Carcangiu ML, Herrington CS, Young RH (eds) (2014) WHO Classification of Tumours of Female Reproductive Organs. 4th edn. IARC Press: Lyon, France.

Kurman RJ, Shih Ie M (2011) Molecular pathogenesis and extraovarian origin of epithelial ovarian cancer-shifting the paradigm. Hum Pathol 42(7): 918-931.

Mackenzie R, Talhouk A, Eshragh S, Lau S, Cheung D, Chow C, Le N, Cook LS, Wilkinson N, McDermott J, Singh N, Kommoss F, Pfisterer J, Huntsman DG, Kobel M, Kommoss S, Gilks CB, Anglesio MS (2015) Morphologic and molecular characteristics of mixed epithelial ovarian cancers. Am J Surg Pathol 39(11): 1548-1557.

Malpica A, Deavers MT, Lu K, Bodurka DC, Atkinson EN, Gershenson DM, Silva EG (2004) Grading ovarian serous carcinoma using a two-tier system. Am J Surg Pathol 28(4): 496-504.

Mavaddat N, Barrowdale D, Andrulis IL, Domchek SM, Eccles D, Nevanlinna H, Ramus SJ, Spurdle A, Robson M, Sherman M, Mulligan AM, Couch FJ, Engel C, McGuffog L, Healey S, Sinilnikova OM, Southey MC, Terry MB, Goldgar D, O’Malley F, John EM, Janavicius R, Tihomirova L, Hansen TV, Nielsen FC, Osorio A, Stavropoulou A, Benitez J, Manoukian S, Peissel B, Barile M, Volorio S, Pasini B, Dolcetti R, Putignano AL, Ottini L, Radice P, Hamann U, Rashid MU, Hogervorst FB, Kriege M, van der Luijt RB, Hebon, Peock S, Frost D, Evans DG, Brewer C, Walker L, Rogers MT, Side LE, Houghton C. EMBRACEWeaver J, Godwin AK, Schmutzler RK, Wappenschmidt B, Meindl A, Kast K, Arnold N, Niederacher D, Sutter C, Deissler H, Gadzicki D, Preisler-Adams S, Varon-Mateeva R, Schonbuchner I, Gevensleben H, Stoppa-Lyonnet D, Belotti M, Barjhoux L, Collaborators GS, Isaacs $\mathrm{C}$, Peshkin BN, Caldes T, de la Hoya M, Canadas C, Heikkinen T, Heikkila P, Aittomaki K, Blanco I, Lazaro C, Brunet J, Agnarsson BA, Arason A, Barkardottir RB, Dumont M, Simard J, Montagna M, Agata S, D'Andrea E, Yan M, Fox S, kConFab I, Rebbeck TR, Rubinstein W, Tung N, Garber JE, Wang X, Fredericksen Z, Pankratz VS, Lindor NM, Szabo C, Offit K, Sakr R, Gaudet MM, Singer CF, Tea MK, Rappaport C, Mai PL, Greene MH, Sokolenko A, Imyanitov E, Toland AE, Senter L, Sweet K, Thomassen M, Gerdes AM, Kruse T, Caligo M, Aretini P, Rantala J, von Wachenfeld A, Henriksson K, Collaborators S-B, Steele L, Neuhausen SL, Nussbaum R, Beattie M, Odunsi K, Sucheston L, Gayther SA, Nathanson K, Gross J, Walsh C, Karlan B, Chenevix-Trench G, Easton DF, Antoniou AC. Consortium of Investigators of Modifiers of B (2012) Pathology of breast and ovarian cancers among BRCA1 and BRCA2 mutation carriers: results from the Consortium of Investigators of Modifiers of BRCA1/2 (CIMBA). Cancer Epidemiol Biomark Prev 21(1): 134-147.

McAlpine JN, Wiegand KC, Vang R, Ronnett BM, Adamiak A, Kobel M, Kalloger SE, Swenerton KD, Huntsman DG, Gilks CB, Miller DM (2009) HER2 overexpression and amplification is present in a subset of ovarian mucinous carcinomas and can be targeted with trastuzumab therapy. $B M C$ Cancer 9: 433.

McCluggage WG (2011) Morphological subtypes of ovarian carcinoma: a review with emphasis on new developments and pathogenesis. Pathology 43(5): 420-432.

Poulsen H, Taylor C, Sobin L (1975) Histological Typing of Female Genital Tract Tumours. World Health Organization: Geneva, Switzerland.

Prat J (2012a) New insights into ovarian cancer pathology. Ann Oncol 23 (Suppl 10): x111-x117.

Prat J (2012b) Ovarian carcinomas: five distinct diseases with different origins, genetic alterations, and clinicopathological features. Virchows Arch 460(3): 237-249.

Schrader KA, Hurlburt J, Kalloger SE, Hansford S, Young S, Huntsman DG, Gilks CB, McAlpine JN (2012) Germline BRCA1 and BRCA2 mutations in ovarian cancer: utility of a histology-based referral strategy. Obstet Gynecol 120(2 Pt 1): 235-240.

Scully RE (1999) World Health Organization International Classification of tumours. Histological Typing of Ovarian Tumors. Springer: Berlin, Heidelberg, New York, Tokyo.

Singer G, Kurman RJ, Chang HW, Cho SK, Shih IeM (2002) Diverse tumorigenic pathways in ovarian serous carcinoma. Am J Pathol 160(4): $1223-1228$.

Srigley JR, Delahunt B, Eble JN, Egevad L, Epstein JI, Grignon D, Hes O, Moch H, Montironi R, Tickoo SK, Zhou M, Argani P, Panel IRT (2013) The International Society of Urological Pathology (ISUP) Vancouver 
Classification of Renal Neoplasia. Am J Surg Pathol 37(10): 1469-1489.

Tavassoli FA, Devilee P (2003) Pathology and Genetics of Tumours of the Breast and Female Genital Organs. IARC Press: Lyon, France.

Wolff AC, Hammond ME, Hicks DG, Dowsett M, McShane LM, Allison KH, Allred DC, Bartlett JM, Bilous M, Fitzgibbons P, Hanna W, Jenkins RB, Mangu PB, Paik S, Perez EA, Press MF, Spears PA, Vance GH, Viale G, Hayes DF. American Society of Clinical OncologyCollege of American Pathologists (2013) Recommendations for human epidermal growth factor receptor 2 testing in breast cancer: American Society of Clinical Oncology/ College of American Pathologists clinical practice guideline update. J Clin Oncol 31(31): 3997-4013.

This work is published under the standard license to publish agreement. After 12 months the work will become freely available and the license terms will switch to a Creative Commons AttributionNonCommercial-Share Alike 4.0 Unported License. 